\title{
Tertiary Students' Perceptions Regarding the Challenges to Develop Writing Skills
}

\author{
Susmita S. Shuvra ${ }^{1, *} \&$ Sukanto Roy ${ }^{2}$ \\ ${ }^{1}$ Department of English \& Modern Languages, North South University, Bangladesh \\ ${ }^{2}$ Department of English and Modern Languages, North South University, Bangladesh \\ *Correspondence: Department of English \& Modern Languages, North South University, Bangladesh. E-mail: \\ susmita.shuvra@northsouth.edu
}

Received: June 8, $2021 \quad$ Accepted: Septe ber 15, $2021 \quad$ Online Published: September 19, 2022

doi:10.5430/ijelt.v9n1p46 URL: https://doi.org/10.5430/ijelt.v9n1p46

\begin{abstract}
Writing is the pivotal skill for the communicative purposes. In the tertiary level, the learners in Bangladesh encounter different types of problems in developing writing skills. However, this is very essential for them to recognize the problems and work out with that. This study is qualitative in nature, analyzes the problems in developing writing skills at the tertiary level in Bangladesh. This is based on secondary data. The data are collected from the other researchers' research papers. Due to the pandemic situation, it could not be possible to collect primary data. The paper starts with describing the background of the writing skills, and approaches in Bangladesh. It also discussed the perspectives of the learners' and teachers' about the developing process of writing skills. Based on the previous research, it represents that lack of enthusiasm of instructors, lack of motivation of learners, institutional constraints hinder the process of developing writing skills at the tertiary level. The paper provides some proposals for resolving the problems that inhibit the process of developing writing skills. At last, this study suggested the implications of further research for identifying the other's challenges and find out the infusion of the challenges. This research received no specific grant from any funding agency in the public, commercial, or not-for-profit sectors.
\end{abstract}

Keywords: writing challenges at tertiary level, the background of the writing skills in Bangladesh, Challenges to develop writing skills, tertiary student's perceptions, possible solutions

\section{Tertiary Students' Perceptions Regarding the Challenges to Develop Writing Skills}

Writing is the process of consistently making good decisions about words, structure, drafting, and editing. This is a cultivated skill. This is also stated as a productive skill. Writing goes through a process to become a product. According to Akter (2016) "Writing is considered as a productive skill because the writer creates new language" (p.1). When people start writing in a new language, it is common to face various types of problems. It is habitual that the writer will face problems in developing writing skills. Writing has huge ramifications on factual life. In Bangladesh, tertiary-level learners are confronting enormous obstacles to develop their writing skills.

There are significant constraints that hinder the process of developing writing skills. English is the global language that is also known as lingua franca in the current world. People learn English for different reasons. In every field, English is necessary. After completing the secondary level, learners pursue study at the tertiary level where the English language is almost in every field. In these circumstances, they try to swim but cannot cross such a big sea smoothly. Writing is one of the crucial parts of the English language. From primary to secondary level in Bangladesh, learners go through various types of writing activities. Evermore, at the tertiary level, the learners cannot manifest their confidence in writing skills. This happens because of the examination patterns and the way of teaching writing. At the root level, learners exist in a fixed table. Secondary school certificate (SSC), and Higher secondary certificate (HSC) examination put stress on memorizing skills and the potentiality of highlighting them through their piece of writing. For that reason, learners cannot able to strengthen their starting point. When learners are asked to write any academic writing, they feel the necessity of the sample (Sadia, 2019). It exhibits that the learners are lag behind.

In Bangladesh, tertiary education entails with public universities, private universities, national universities, and 
medical colleges. The learners choose different types of specific programs at this level. In private universities and medical colleges, the courses are taught in English. In the public university, some courses are taught in English and some courses are taught in Bangla. On the other hand, particularly the English subject is taught in English and others are taught in Bangla at National University. Only private University offers some foundation English courses for all the program. These courses are proposed to develop the writing skill of the learners. However, other tertiary-level educational institutions do not provide these courses. So, the learners of these institutions cannot get the opportunity to build their writing skills in English. Standard writing skills in English are now appraised in every job sector of Bangladesh, (Sadia, 2019). As a consequence, the learners are needed to indulge in the scope for developing writing skills.

It is perceived that learners' lack of interest in English baffles the process of developing writing skills (Afrin, 2016). In Bangladesh, Bangla is the mother tongue. Learners learn English in the EFL context where they are taught English as a subject rather than a language. It influences the way of improving their writing skills. They do not feel motivated. They do not get a chance to use the language for authentic purposes. Learners are suppressed by the fixed writing activities in the classroom. They cannot be able to think by themselves because of the fixed decorum. That's why most of the learners unable to develop their writing skills after reading English for 10 to 12 years. The learners who do not have ample knowledge of writing skills in English will have to go through many storms in educational and professional life.

\subsection{Statement of the Problem}

In the globalized world, writing plays a vital role in establishing a career. In this situation, most of the learners are not confident about their writing skills in Bangladesh. There are various types of reasons for this issue. At the tertiary level, learners are expected to have fair apprehension on writing skills. Merely, they are not able to delineate their skills. They face immense problems. It is pivotal to find out the reasons behind this and what instructors' and learners' anticipation about this point. In the mid-twentieth century, English is spread all over the world. So, people cannot overlook the importance of writing skills in English. So, it is indispensable to find out the challenges of developing writing skills at the tertiary level of Bangladesh.

\subsection{Research Objective}

The objective of the paper is to investigate the challenges developing writing skills at the tertiary level of Bangladesh. The research will focus on the instructors' and learners' perceptions about the problems. The findings of the research would have the potential to help the tertiary level teachers' to develop the learners' writing skills. It would also specify the major problems and help learners become aware of writing mistakes. It would also describe what steps are needed to take for bringing change in the assessment system of the writing skills at the tertiary level. Moreover, it might have been able to give the possible solutions to the problems after the specifications.

\subsection{Research Question}

Based on the research objectives the following questions have been organized to scrutinize the circumstances:

a) What are the challenges that hinder the process of developing writing skills at the tertiary level of Bangladeshi?

b) What are the instructors' and learners' perceptions of this issue?

c) What are the possible solutions to improve the situation?

In the upcoming sections, I will discuss the issues and challenges regarding developing writing skills. Then, I will look over the cognition of instructors and learners about the matter. I will dispute the strategies which are necessary to execute at the tertiary level of Bangladesh to upgrade the situation. Further, I will discuss the recommendation for the writing assessment process of tertiary level learners'. At length, the imputations of further research will be considered.

\section{Literature Review}

In this section, there is a scenario of my analysis about this research topic. I have fabricated the summary of the knowledge obtained from the history and gist from the literature. My discussion starts with the background of developing the writing problems, and writing approaches. After that, a detailed discussion on the teachers' and learners' perspectives. Then, the recommendations of the writers about the emulsion of the problem. 


\subsection{Challenges of Developing Writing Problem}

There are several problems in the root level learning system of the learners which hinders writing skill development. At the secondary and primary levels, some specific layouts of writings are taught. The students face problems with paragraph, essay, story, and summary writing. It happens because they cannot come up with their creative ideas. They are living in a decorum. So, they cannot be able to show their creativity. In the Bangla medium, students do not get the chance to show their ability in creative writing. They do not receive enough guidance from the teachers. It occurs because the teaching-learning process is going through based on some particular books at the primary and secondary levels (Akhter, 2016).

The importance of motivation in developing writing skills is indispensable. The learners are not able to improve their writing skills because of the lack of ideas, and lack of motivation. They cannot able to put their ideas into their piece of writing. The authors have done a survey, and the data showed that students brainstorm to gather ideas, but they have insufficient knowledge about the techniques of listing, and clustering. For this reason, they unable to assemble their ideas. They are always conscious of their grammatical errors. The current pedagogical system cannot able to recover the situation (Patwary \& Sajib, 2018).

Teachers' attitudes can bring change in the development process of writing skill. The teachers' lack of enthusiasm hinders the process of developing writing skills. The courses have fixed syllabus for a long time. So, the teachers do not take any preparation. They only do their duty by completing the syllabus. Some teachers stimulate the learners for creative writing. Most of the teachers are concern about the grammatical errors of the learners. They do not encourage the creativity of the learners, which demotivates the learners from further writing (Sadia, 2019).

Neil deGrasse Tyson (1998; as cited in Ahmed and Karunakaran, 2013) points out, "Teaching of writing in the USA and the UK have long back shifted its attention from dealing with the finished product of writing to the processes of writing" (p.109). So, the process has been changed in the others countries, though Bangladesh follows the traditional approach. So, Bangladeshi learners are facing problems in writing skills because of the process.

Learners face problems to assemble their ideas. They face problems in paragraph writing. There are three stages of paragraph writing such as planning, writing, and revising. In the compare-contrast paragraph, the learners need to shift from one idea to another idea. They need to list the points of the topic. They face difficulties in the thought process. They also face problems with grammatical functions, when they try to write a paragraph. They cannot exhibit their thought in the writing. They cannot do brainstorm properly (Karim et al., 2017).

\subsection{Approaches to Writing Skills}

To improve writing skills, approaches play a dominant role. There are two approaches to writing skills. One is the product approach, another is the process approach. There are some features of the teaching process of the product approach. The writing mechanics are taught in this approach. The errors are treated by giving proper guidelines. The specific motif of this approach is to help the learners to become proficient in their required writing field. On the other hand, in the process approach, the writers learn how to arrange the ideas of the writing (Tina, 2018). There is another approach. This is called "genre approach". Genre approach is the addition of product approach where the main focus is linguistic elements. This also emphasizes the varieties of writings based on the different social contexts. The genre approach is the latest in the field of ELT. It helps learners to write what they are required for a particular field. Various countries already applied this approach in the educational field (Hasan, 2011).

\subsection{Teachers' Perspective}

The teachers emphasize the grammatical functions of the writing skill. At the secondary, and primary levels, teachers want to make the students prepare for the tertiary level. They believe that there is a necessity of getting exposure to authentic writing tasks for the learners. Though teachers have pedagogical beliefs about writing, they are not able to demonstrate their perception through the practice because of some constraints. Teachers need proper training so that they can apply different approaches in the classroom for improving the writing skills of the learners and create a sense among them that writing is one of the parts of social interaction (Uddin, 2014).

This is not the only duty of the teachers to take the step for the learners, but the guardian also plays a crucial role in developing the writing skills of the learners. Teachers argued that most of the guardians are not acquainted with their children's skills. They think that students should be prepared for the examination. They have to do a good result. The guardian also needs to give focus on their children's studies. They want that teachers should teach what will appear in the examination which baffles the process of developing writing skills (Sadia, 2019). 


\subsection{Learners' Perspective}

Learners point out some specific problems that they face. Most of the students suggest that written response helps them to improve their skills at the primary and secondary levels. They also claimed that teachers and home tutors give them responses but that is not enough for them. The students express their thoughts about writing. They want to improve their writing. They want to display their creativity in the composition part (Akhter, 2016).

An unfriendly environment hampers the process of learning. Learners asserted that the teachers do not allow their opinion. The teacher-student relationship is not workable which creates an unfriendly environment for learning. They also claimed that teachers are biased. They give priority to first-ranking students which discourage other learners in the classroom. Teachers said that to write what is written in the book, and do not emphasize them for writing by themselves. This type of attitude does not help learners to write something different (Sadia, 2019)

Fundamental courses help learners to enhance their writing skills in the tertiary-level. EAP (English for Academic Purpose) courses improve learners' writing skills. He has taken the interview of some tertiary-level learners. They said that EAP courses are very helpful. EAP teachers also help them to be proficient in the second language. After EAP 1 course, the authority needs to offer some advanced courses, because EAP 2 course is similar to the EAP 1 which is not able to meet their expectations (Nahiyan, 2018).

\subsection{Writers'Recommendations}

Different types of writers manifest distinct types of directions to improve the writing skills of tertiary-level learners. To polish the writing skill of the learners, it is important to introduce language courses in other departments besides English to provide them the opportunity to improve their writing capability. The learners who do not have adequate knowledge on how to write compositions in an academic setting, there is an exigency to give special attention to them. The traditional teaching method should be changed. The language teachers are required to exploit modern methods to improve the learners' skills. Learners should maintain a vocabulary diary. Teachers should ply modern aid. The examination questions should be creative, not tedious. Teachers need to encourage students through various types of writing tasks that allow them to think critically and give them feedback properly (Afrin, 2016). The traditional way of teaching inhibits the way of developing writing skills. The teacher should follow the contemporary style of teaching. The teachers are required to teach the basics and strategies of writing so that the learners will be able to write in the exam paper as well as gain the ability to create writing on any topic. So, there is a necessity of introducing writing courses in the L1 language, after that in the L2 language. The proper training is also needed to provide the teachers so that they can carry out their teaching process successfully (Mustaque, 2014).

Feedback plays a dominant role in developing writing skills. For providing proper feedback, the class size is required to be kept compact. Productive feedback should be proffered to the learners. Common mistakes can be mentioned in general. The teachers need to create a suitable platform for learners to give feedback. Learners should be allowed to ask questions for their any queries related to the writing skills. Teachers can pick which errors are needed to correct, and which are not. The most potential matter is that they should just not only correct the learners' grammatical errors, but also the problems in writing structure (Karim \&Ivy, 2011). Proper input can help to develop writing skills of the learners at the tertiary level. Exact input can help to develop the writing skills. Writing criteria can be changed depending on the situation. Learners need different types of writing strategies to apply in their professional purpose. So, they need specific types of input which can help them to develop writing skills for their purpose (Hasan, 2011).

Sadia (2019) stated, "Creative writing should be rewarded than memorized answers" (p.37). According to her, if learners are allowed to show their creativity in writing, they will learn how to write on their own. They will not just memorize that comes in the exam. They will aware of developing writing skills. The Syllabus needs to be updated in the tertiary level. The teachers need time to understand the level of the learners. Learners came from different backgrounds. They have different types of needs. The authority needs to introduce some courses according to the learner's needs. A course syllabus needs to be updated according to the requirements of the learners. The CLT (Communicative Language Teaching) method should be applied at this level to improve the learners' writing skills. The grammatical errors must be corrected to develop their writing capability in the second language. There is a necessity of need analysis. The important fact is that syllabus designers, materials designers, and textbook writers need to a survey to find out the problems of the tertiary level learners. If they can find out the problem area, they can easily get the emulsion of the problems (Fahmida, 2010).

Several factors are needed to be changed. Proper care and encouragement are necessary for the learners at the root level. Teachers need to make rapport with the learners. They need to monitor the learners in the practice stage. Teachers need pedagogical training. The institutions should recruit teachers who are specialized in a specific field. 
Their salary needs to be increased which can motivate them to show their real passion. Institutions can arrange the competition which can help learners to write creative writing (Tina, 2016). Learners face problems in paragraph writing. It can be solved by proper monitoring. Teachers should focus on the different features and types of paragraph writing. To improve the learners' composition writing, the teachers need to help the learners to develop their vocabulary, idioms, and other elements of writing. Institutional administrators and policy-makers should provide training for developing the learners' required skills. They need to make changes in the education policy for developing the learners' writing skills (Karim, 2017). Sub skills are needed to be polished to develop the writing skills of the learners. Sub-processes including reading, understanding, and linking ideas can help learners to improve their writing capability. Teachers should emphasize the "summary writing" of the learners that express their writing proficiency (Ahmed \& Karunakaran, 2013). Learners are needed to engage in tasks to develop their writing. They should allow them to do the tasks by themselves. Teachers should monitor them in this process. They are required to maintain a portfolio of their writing. The teachers should give them quick responses. Teachers also need to give them proper information about their examination and assessment process. Learners need to show their drafts for being proficient in writing. The cooperative attitude among the teachers at the tertiary level can make the process of developing writing skills easy. (Huda \& Kamal, 2011)

\section{Discussion \& Conclusion}

The research represents the scenario of the background of developing the writing process in Bangladesh. The learners from the root level to the tertiary level face several types of problems when they want to write compositions by themselves. It is signified through the data that learners are not motivated for improving their writing skills. On the other hand, teachers are not showing their real passion for teaching. These causes several problems in the developing writing skill process. This is not true that all learners are not motivated. Many learners want to improve their proficiency level in writing. Sometimes, they are not getting the proper opportunity. On the contrary, many teachers want to encourage learners to creative writing, but they are facing limitations. The policy-makers need to do need analysis for finding out the requirements of the learners. It has been clear that many countries have already educational changes, where Bangladesh is lagging behind. Most of the Bangla medium schools are still now following traditional approaches. The institutions which are following modern approach, are not getting a friendly environment to apply the approach properly. Syllabuses are needed to be updated according to the learners' level. Some new courses are needed to be provided. The problems at the root level hinder the development process at the tertiary level. This is not possible to make the learners proficient instant. It is a long process. So, if the authority takes steps only at the tertiary level, this problem will not be solved. Some crucial courses can help the learners to improve their errors, but they cannot make them proficient in writing skills. According to Ahmed and Karunakaran (2013), "writing is a thought process during which words are put together to convey one's ideas and emotions" (p.103). It is clear that to put the information in the piece of writing, it is necessary to practice the discrete features of writing.

This is true that only teachers and institutions' authority cannot change the situation. The guardian also needs to take the step. They should motivate their learners for creative. This is true that only teachers and institutions' authority cannot change the situation. The guardian also needs to take the step. They should motivate their learners for creative

*The different writing approaches are needed to be applied according to the performance of the learners. If in the middle, any changes are required, teachers and authority should take steps for this.

*At the root level, the authority and teachers should not make the lesson plan only according to the examination. They need to emphasize creative writing skill.

* Exam-based assessment should be changed. If the assessment process is done depending on the learners' skills, they will be motivated to develop their writing skills.

*The foundation courses of English are needed to introduce in the National University and Public University which will be very beneficial for the learners.

*At the tertiary level, teachers need to apply 3P (Presentation, Practice, Production) techniques. They can also apply Bloom's taxonomy in the class. This will allow learners to share their ideas, and do writing tasks by themselves.

*The teachers need to specify the problems of individual learners in writing skills. They need to apply "beyond method" to solve the problems of the learners.

*Learners should make their own "agency" of writing. They need to keep their voice in writing. 
This is the fact that in Bangladesh there are lots of limitations in institutions. The learners are not getting more opportunities. It is not possible to make the change over time. It will take time. This study mainly represents the problems at the tertiary level for developing writing skills. The study exhibits the short scenario. This study will be helpful to identify the problems and take proper steps based on these facts.

\section{References}

Afrin, S. (2016). Writing problems of non-English major undergraduate students in Bangladesh: An observation. Open journal of social sciences, 4(3), 104-115.

Ahmed, Z., \& Karunakaran, T. (2013). Teaching writing: An analysis of the writing tasks used at East West University in Bangladesh. Language in India, 13(3), 103-117.

Akhter, I. (2016). Effectiveness and difficulties of creative writing in language learning: a study of secondary level Bangla medium schools in Dhaka city (Doctoral dissertation, BRAC University). Retrieved from http://dspace.bracu.ac.bd/xmlui/bitstream/handle/10361/7820/15163012_ENH.pdf?sequence=1\&isAllowed=y

Fahmida, B. (2010). Bangladeshi tertiary level students' common errors in academic writing (Doctoral dissertation, BRAC University).

Retrieved fromhttp://dspace.bracu.ac.bd/xmlui/bitstream/handle/10361/252/08163004.PDF?sequence=4\&isAllowed=y

Hasan, M. K. (2011). Approaches to the teaching second language writing at tertiary level in Bangladesh private universities. ABAC Journal, 31(1).

Huda, S., \& Kamal, N. (2011). Classroom experience of teaching-writing to undergraduate students: Bangladesh context. Eastern University Journal, 3(2).

Karim, M. Z., \& Ivy, T. I. (2011). The nature of teacher feedback in second language (L2) writing classrooms: A study on some private universities in Bangladesh. Journal of the Bangladesh Association of Young Researchers, 1(1), 31-48.

Karim, S. M., Sanaul, Maasum, T. N., Rizan Tg Mohd, \& Latif, H. (2017). Writing Challenges OF Bangladeshi Tertiary Level EFL learners. Journal of Social Sciences and Humanities, 12 (2), 296-306.

Mustaque, S. (2014, January). Writing Problem among the Tertiary Level Students in Bangladesh: A Study in Chittagong Region, Language in India, 14(1), 327-391.

Nahiyan, S. (2018). Appropriateness of EAP courses at tertiary level: an intra-university study in Bangladesh (Doctoral dissertation, BRAC University). Retrieved from http://dspace.bracu.ac.bd/xmlui/bitstream/handle/10361/10793/15103005_ENH.pdf?sequence=1\&isAllowed=y

Patwary, M. N., \& Sajib, M. N. F. (2018). Improving Writing Skills in English at the Tertiary Level: The Gap between the Standard Practice and Classroom Scenario. A Journal of English Studies, 9.

Sadia, N. (2019). Teachers' classroom practices and their impact on student's English writing skills: a qualitative study of three schools in a small town in Bangladesh (Doctoral dissertation, Brac University). Retrieved from http://dspace.bracu.ac.bd/xmlui/bitstream/handle/10361/12310/15103035_ENH.pdf?isAllowed=y\&sequence=1

Tina, A. A. (2016). The Problems Students Face in Developing Writing Skill: A study at Tertiary Level in Bangladesh. IUB Academic Repository. Retrieved September 29, 2020, from http://dir.iub.edu.bd:8080/xmlui/handle/123456789/45

Uddin, M. (2014). Teachers' Pedagogical Belief and Its Reflection on the Practice in Teaching Writing in EFL Tertiary Context in Bangladesh. European Journal of Educational Sciences, 1(3), 58-80.

\section{Copyrights}

Copyright for this article is retained by the author(s), with first publication rights granted to the journal.

This is an open-access article distributed under the terms and conditions of the Creative Commons Attribution license (http://creativecommons.org/licenses/by/4.0/). 